\title{
SECONDARY INFLUENCES FROM X-RAY IRRADIATION ON MUTATIONAL PROCESSES IN DROSOPHILA MELANOGASTER
}

\author{
GERT BONNIER \\ Institute of Genetics, University of Stockholm, Stockholm, Sweden
}

Received 17.vi.53

\section{INTRODUCTION}

IN two earlier papers (Bonnier, Lüning and Arnberg, I952; Bonnier and Lüning, I953) it was shown that recessive sex-linked lethals in the spermatozoan chromosomes of Drosophila melanogaster are produced at a higher rate when the sperm is X-rayed in impregnated females than when the irradiation is given to males. In the first of these papers this fact was taken as an indication of a possible indirect effect through the egg cytoplasm of the irradiation. But in the second paper it was found that when the irradiation was given to both males and females, though to the females before mating, this did not result in any increase in percentage of sex-linked lethals in the paternal $\mathrm{X}$-chromosomes.

During the sequence of the experiments Dr Lüning had made much use of the fact that after irradiation of the so-called $M_{5}$ (Muller 5) X-chromosome $\left(s c^{S_{1}} B I n-S w^{a} s c^{8}\right)$ there occur breaks which manifest themselves as yellow mutations (Belgovski, 1938, 1939). It was, hence, decided to take up this technique for further analyses of the present and allied questions. These studies were made as a joint investigation by Dr Lüning and myself, but since our purposes, and the problems which we wished to elucidate, were somewhat dissimilar we now publish the results separately. The reader is, however, advised to take account also of the paper by Dr Lüning which follows after the present one. The material of our two papers coincides to a large extent. The great majority of the countings and the classifications of the flies were made by Dr Lüning and I am very much indebted to him for the great aid he thus has given me. The irradiation technique is described in his paper. The methods of the crossings for the present investigation are described in the table headings.

\section{THE EXPERIMENTS}

The experiments were undertaken in three sets. When a first set of experiments was ready the results showed that another set had to be made, and, when this was ready, it was necessary to perform still one more set. In all experiments, females which were homozygous yellow (and besides that, in some experiments, white, singed and in other experiments, achete, scute, prune, singed) were crossed 
to $M_{5}$ males. The offspring containing aberrations in the paternal $\mathrm{X}$-chromosomes was classified in the following 3 classes. I. full yellow females; 2. fractional yellow females (which are yellow on a part of the body and grey on the rest ; $c f$. discussion) ; 3 . hyperploid males (which contain one maternal and one paternal X-chromosome,

\section{TABLE I}

Progeny from the cross y w sn females, 2-4 days of age, to $\mathrm{M}_{5}$ males. Mode of irradiation was as follows. Series $M$, only males irradiated; series $v F-M$, virgin females and males irradiated; series i $F-M$, irradiation given to impregnated females; series $F$, only females irradiated. The dose was $3000 \mathrm{r}$ in all series except series $F_{2}$ in which it was rooo $r$. The series $M_{2}$ and vF-M2 were irradiated together, i.e. a group of males was treated under a common $X$-ray beam and after irradiation the males were separated into two parts of which one was mated to non-treated virgin females (series M2) and one was mated to virgin females which were treated simultaneously with the males (series $v F-M_{2}$ ). Two repeats were made within these series. The other series were irradiated separately. The age of the males was 2-4 days at treatment except series $M_{I}$ in which the males were of $0-I$ days of age.

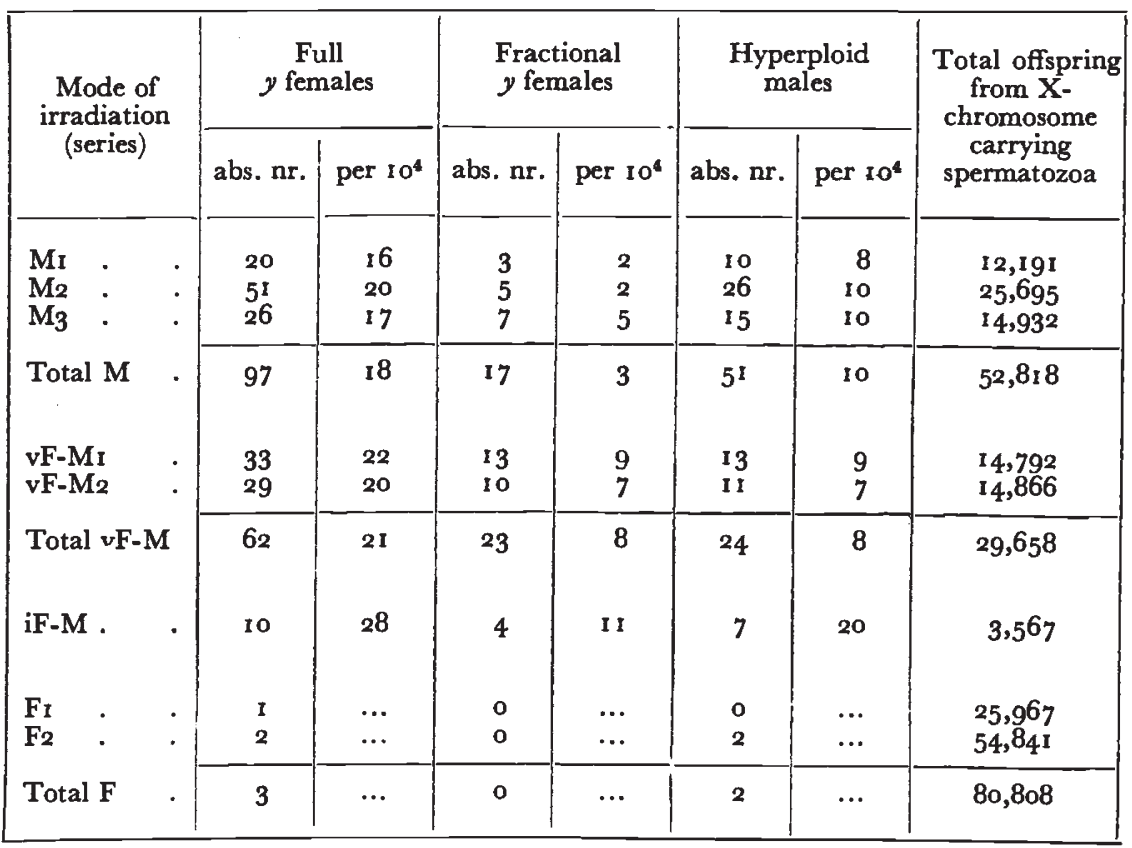

Fractionals in series vF-M vs. series $\mathrm{M}, \chi_{\mathrm{c}}^{2}=7 \cdot 2, \mathrm{P}=0 \cdot 007$.

Fractionals in series vF-M2 vs, series $\mathrm{M}_{2}$, exact statistical method, $P=0.02$.

the latter, however, consisting of the distal tip and the centromeric region only ; they are non-yellow and sterile). Besides these aberrants there occur variegated individuals with a limited number of yellow hairs intercalated between the grey hairs ( $c f$. discussion); they are in the tables included among the normal offspring and thus not separately classified. In the progeny of $y$ ac sc pn sn females there occurred a small number of yellow variegations, i.e. females which 
are practically wholly yellow but with a few grey hairs; these are included among the yellow females (see tables 2 and 3 ).

The irradiations were made in four different ways which will be denoted by the symbols $\mathrm{M}, \mathrm{vF}-\mathrm{M}, \mathrm{iF}-\mathrm{M}$ and $\mathrm{F}$ : $\mathrm{I}$. irradiation of males only $(\mathrm{M})$; 2. irradiation of males and of virgin females prior to mating ( $\mathrm{vF}-\mathrm{M})$; 3. irradiation of impregnated females (iF-M); 4. irradiation of virgin females only $(\mathrm{F})$.

In the first set of experiments $y w$ sn females, 2-4 days old, were mated to $M_{5}$ males the spermatozoa of which were given an X-ray dose of $3000 \mathrm{r}$ at an age of the males of 2-4 days (in one series $0-1$ days, see table I). In conformity with our earlier observations a higher rate of some of the mutational processes is found when the sperm is irradiated in impregnated females than when irradiated in males. The series iF-M was, however, in this case a rather small one and was, accordingly repeated later (table 3 ). Another very interesting result is seen from a comparison of the rates of fractionals in the two series $v F-M$ and $M$. As table $I$ shows, this rate is in series $v F-M$ more than twice that in series M. A $\chi_{\mathrm{c}}^{2}$ test ( $\chi^{2}$ with Yates' correction for continuity) gives $\chi_{\mathrm{c}}^{2}=7 \cdot 2, \mathrm{P}=0^{\cdot 007}$, a very good significance, especially as Yates' correction gives somewhat too large a value to $\mathbf{P}$. Now, not all series included in table I were made by simultaneous irradiations (see text to the table). If we confine ourselves to the two series $\mathrm{M}_{2}$ and $v F-\mathrm{M}_{2}$ in which the sperm was treated by the very same X-ray beam, the totals are of course diminished and, hence, the level of significance reduced. But applying the exact method, the probability of getting a fit as bad or worse than that found (including both tails) is still as small as $0 \cdot 02$.

The conclusion which thus must be drawn is that irradiation of the virgin $y w s n$ females enhances the effect of the irradiation of the $M_{5}$ males in the production of fractional yellow daughters. That this is not an effect of the irradiation of the females by itself is concluded from the result of the $\mathrm{F}$ series, in which not a single fractional was found in totals of 25,967 (3000 r) and 54,84I (I000 r).

With these conclusions in mind it seemed to be of interest to try to elucidate if the enhancing effect of irradiating virgin females on the production of fractionals from irradiated males was a stable one or if it would disappear after a short while. For this reason a second set of experiments was started in which the two modes of irradiation, $\mathbf{M}$ and $v F-M$, were compared in conjunction with a study of the influence of length of time from irradiation of the females to fertilisation of their eggs (table 2). In the series $v F-M$ two different treatments were, therefore, made. In the first, virgin females of 2-4 days of age, were irradiated (3000 r) and immediately thereafter mated to $M_{5}$ males, 3-4 days of age, which, under the same X-ray beam, also got $3000 \mathrm{r}$ (series vF-M(2)). For comparison, a lot of the so irradiated males was mated to untreated virgin females, 2-4 days of age (series $\mathbf{M}(2)$ ). In the second kind of treatment virgin females, 2-4 days 
of age were irradiated with $3000 \mathrm{r}$, thereafter kept without males for a week and then mated to $M_{5}$ males, 3-4 days of age which had got $3000 \mathrm{r}$ (series $\mathrm{vF}-\mathrm{M}(9)$ ) ; and, for comparison a lot of these males was mated to untreated virgin females of 9-I I days of age (series $\mathbf{M}(9)$ ). A series with irradiation of impregnated females (series iF-M) was also included in these experiments. These females were 2-4 days of age and they were irradiated under the same X-ray beam as the corresponding males (see text to table 2).

TABLE 2

Progeny from the cross y ac sc pn sn females to $\mathrm{M}_{5}$ males. Dose in all series 3000 r. A group of males, 2-4 days of age, was irradiated under a common $X$-ray beam. After irradiation the males were separated into four parts: $I$. one part was mated to nontreated virgin females, 3-4 days of age, series $M(2)$; 2. one part was mated to nontreated virgin females, $9-I I$ days of age, series $M(9)$; 3 . one part was mated to virgin females, 2-4 days of age, which had been subjected to the same $X$-ray beam as the males, series $v F-M(2)$; 4. one part was mated to virgin females, 9-II days of age, which were given $3000 \mathrm{r}$ a week earlier, series $v F-M(g)$. The males were taken away from the females one day after beginning of mating. The very same males had, during the day before their irradiation been mated to virgin females, 2-4 days of age, and these females were then irradiated together with the males under the same $X$-ray beam, series $i F-M$. The series $M(2), v F-M(2)$ and $i F-M$ were repeated for a total of 4 times, and the series $M(9)$ and $v F-M(g)$ for a total of 5 times.

\begin{tabular}{|c|c|c|c|c|c|c|c|}
\hline \multirow{2}{*}{$\begin{array}{l}\text { Mode of } \\
\text { irradiation } \\
\text { (series) }\end{array}$} & \multicolumn{2}{|c|}{$\begin{array}{c}\text { Full } \\
y \text { females }\end{array}$} & \multicolumn{2}{|c|}{$\begin{array}{l}\text { Fractional } \\
y \text { females }\end{array}$} & \multicolumn{2}{|c|}{$\begin{array}{l}\text { Hyperploid } \\
\text { males }\end{array}$} & \multirow{2}{*}{$\begin{array}{l}\text { Total offspring } \\
\text { from X- } \\
\text { chromosome } \\
\text { carrying } \\
\text { spermatozoa }\end{array}$} \\
\hline & abs. $\mathrm{nr}$. & per $10^{4}$ & abs. $\mathrm{nr}$. & per $10^{4}$ & abs. $\mathrm{nr}$. & per $10^{4}$ & \\
\hline $\begin{array}{l}\mathbf{M}(2) \\
\mathbf{M}(9)\end{array}$ & $\begin{array}{l}21^{*} \\
35 \dagger\end{array}$ & $\begin{array}{l}29 \\
29\end{array}$ & $\begin{array}{l}3 \\
3\end{array}$ & $\begin{array}{l}4 \\
3\end{array}$ & $\begin{array}{l}20 \\
21\end{array}$ & $\begin{array}{l}27 \\
18\end{array}$ & $\begin{array}{r}7,3^{6} 5 \\
\text { I } 1,878\end{array}$ \\
\hline Total $\mathbf{M}$ & $5^{6}$ & 29 & 6 & 3 & $4 I$ & 21 & I 9,243 \\
\hline $\begin{array}{l}\text { vF-M(2) } \\
\text { vF-M(9) }\end{array}$ & $\begin{array}{l}31 \dagger \\
37^{*}\end{array}$ & $\begin{array}{l}28 \\
20\end{array}$ & $\begin{array}{r}4 \\
10\end{array}$ & $\begin{array}{l}4 \\
5\end{array}$ & $\begin{array}{l}15 \\
45\end{array}$ & $\begin{array}{l}14 \\
25\end{array}$ & $\begin{array}{l}10,971 \\
18,294\end{array}$ \\
\hline Total vF-M & 68 & 23 & 14 & 5 & 60 & 21 & 29,265 \\
\hline iF-M . & 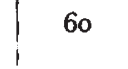 & 27 & 8 & 4 & 63 & 29 & 22,102 \\
\hline
\end{tabular}

* Includes 2 females which had a few grey hairs.

$\dagger$ Includes 3 females which had a few grey hairs.

As mentioned above the females of the first set of experiments (table I) were $y w s n$. The reason for the choice of this strain was that we had used it in several earlier experiments and, hence, knew that it was well suited for our purposes. From the point of view which governed Dr Lüning's purposes it was, with the results of the first set of experiments in mind, of interest to use more markers in the left tip of the X-chromosome (see his paper). And as, from 
the points of view of the present studies, the only necessity seemed to be that the females were yellow, it was agreed that, in the second set of experiments, the females should be taken from a $y$ ac sc pn sn stock. In these experiments it was thus such females which were crossed to $M_{5}$ males.

From table 2 it is found that neither the age difference between the females nor the difference in length of time between irradiation of the females and laying of their eggs produced any appreciable differences in the rates of aberrants. The most surprising result, which at first seemed to contradict our earlier observations, is that when the rates of fractionals are compared for the three modes of

TABLE 3

Comparison of the progeny from $\mathrm{y} \mathrm{w} \mathrm{sn}$ and from $\mathrm{y}$ ac $\mathrm{sc}$ pn $\mathrm{sn}$ females after crossing to $\mathrm{M}_{5}$ males. One part of a group of 3-4 days old males was mated to virgin y w sn females and one part to virgin y ac sc pn sn females, all females of 2-4 days of age. One day later these females and males, together with virgin females of the same two strains and of the same age were irradiated with $3000 \mathrm{r}$ under a common $X$-ray beam. The offspring of the females which were impregnated at irradiation form the series $i F-M$. The offspring of the other females form the series $v F-M$. All series were repeated for a total of 5 times.

\begin{tabular}{|c|c|c|c|c|c|c|c|c|}
\hline \multirow{2}{*}{$\begin{array}{c}\text { Females } \\
\text { to which } \\
\text { the males } \\
\text { were } \\
\text { mated }\end{array}$} & \multirow{2}{*}{$\begin{array}{l}\text { Mode of } \\
\text { irradiation } \\
\text { (series) }\end{array}$} & \multicolumn{2}{|c|}{$\begin{array}{c}\text { Full } \\
y \text { females }\end{array}$} & \multicolumn{2}{|c|}{$\begin{array}{l}\text { Fractional } \\
y \text { females }\end{array}$} & \multicolumn{2}{|c|}{$\begin{array}{l}\text { Hyperploid } \\
\text { males }\end{array}$} & \multirow{2}{*}{$\begin{array}{c}\text { Total } \\
\text { offspring } \\
\text { from X- } \\
\text { chromosome } \\
\text { carrying } \\
\text { spermatozoa }\end{array}$} \\
\hline & & $\begin{array}{l}\text { abs. } \\
\text { nr. }\end{array}$ & $\begin{array}{l}\text { per } \\
10^{4}\end{array}$ & $\begin{array}{l}\text { abs. } \\
\text { nr. }\end{array}$ & $\begin{array}{l}\text { per } \\
\text { I } 0^{4}\end{array}$ & $\begin{array}{l}\text { abs. } \\
\text { nr. }\end{array}$ & $\begin{array}{l}\text { per } \\
\text { 10 }\end{array}$ & \\
\hline$y w s n$ & $v F-M$ & 35 & 26 & I & I & I 4 & IO & 13,403 \\
\hline y ac sc pn sn & $v F-M$ & 19 & 25 & I & I & 16 & 21 & 7,473 \\
\hline$y w s n$ & iF-M & 43. & 27 & I 5 & Io & 31 & 20 & 15,702 \\
\hline y ac sc pn sn & iF-M & $18^{*}$ & 39 & I & 2 & 14 & 30 & 4,621 \\
\hline
\end{tabular}

Fractionals from series $y w s n$ vF-M this table $v s$. corresponding series table $1, \chi_{\mathrm{c}}^{2}=6 \cdot 9$, $\mathbf{P}=$ o.009.

* Includes 2 females which had a few grey hairs.

irradiation, the rates from irradiation of the males only $(\mathbf{M})$ are neither increased by irradiation of the virgin females ( $\mathrm{FF}-\mathrm{M})$ nor by irradiation of the sperm in impregnated females (iF-M). The question therefore arose if the " nature" of the females which are crossed to the $M_{5}$ males is of influence in the production of aberrants from irradiated male gametes. A new set of experiments was, accordingly, started.

In this third set of experiments (table 3) only the two modes of irradiation were made : irradiation of $M_{5}$ males, 3-4 days of age, together with irradiation of virgin females, 2-4 days of age (vF-M); and irradiation of impregnated females (iF-M). The two strains of females $y w s n$ and $y$ ac sc pn sn were used (see text to table 3). Here it is found that, as regards the production of fractionals in the iF-M 
series, the high rate is again restored in the progeny of $y w$ sn females (Io per $10^{4}$ ) and the low rate in the progeny of $y$ ac sc pn sn females (2 per $\left.1^{4}\right)$. Because of the relative smallness of the series $\mathrm{iF}-\mathrm{M}$ from the last type of females, the difference between the two iF-M series is not significant, but is, to say the least, strongly indicative. Another point of surprise is the low rate of fractionals in the vF-M series after $y w$ sn females ( $\mathrm{I}$ in 13,403 ) as compared with the corresponding rate in table I (23 in 29,658). This difference is significant, $\mathbf{P}<0^{\circ} \mathrm{OI}$. Now, as all rates within similar types of series, except the last mentioned one, are of the same order of magnitude, it is quite justified to pool the figures. This is done in table 4 .

TABLE 4

Totals from tables $1,2,3$

\begin{tabular}{|c|c|c|c|c|c|c|c|c|}
\hline \multirow{2}{*}{$\begin{array}{c}\text { Females } \\
\text { to which } \\
\text { the males } \\
\text { were } \\
\text { mated }\end{array}$} & \multirow{2}{*}{$\begin{array}{l}\text { Mode of } \\
\text { irradiation } \\
\text { (series) }\end{array}$} & \multicolumn{2}{|c|}{$\underset{y \text { females }}{\text { Full }}$} & \multicolumn{2}{|c|}{$\begin{array}{l}\text { Fractional } \\
y \text { females }\end{array}$} & \multicolumn{2}{|c|}{$\begin{array}{l}\text { Hyperploid } \\
\text { males }\end{array}$} & \multirow{2}{*}{$\begin{array}{c}\text { Total } \\
\text { offspring } \\
\text { from X- } \\
\text { chromosome } \\
\text { carrying } \\
\text { spermatozoa }\end{array}$} \\
\hline & & $\begin{array}{l}\text { abs. } \\
\text { nr. }\end{array}$ & $\begin{array}{l}\text { per } \\
10^{4}\end{array}$ & $\begin{array}{l}\text { abs. } \\
\text { nr. }\end{array}$ & $\begin{array}{l}\text { per } \\
10^{4}\end{array}$ & $\begin{array}{l}\text { abs. } \\
\text { nr. }\end{array}$ & $\begin{array}{l}\text { per } \\
10^{4}\end{array}$ & \\
\hline$y w s n$ & $\mathbf{M}$ & 97 & 18 & 15 & 3 & $5^{I}$ & 10 & 52,818 \\
\hline y ac scpn sn & & 56 & 29 & 6 & 3 & $4 \mathrm{I}$ & 21 & $\begin{array}{l}19,243 \\
\end{array}$ \\
\hline$y w s n$ & vF-M & 97 & 23 & 24 & 6 & 38 & 9 & 43,061 \\
\hline$y$ ac sc pn sn & vF-M & 87 & 24 & I 5 & 4 & 76 & 21 & 36,738 \\
\hline$y w s n$ & $\mathrm{iF}-\mathrm{M}$ & 53 & 28 & 19 & 10 & $3^{8}$ & 20 & $\begin{array}{l}19,269 \\
196\end{array}$ \\
\hline$y$ ac sc pn sn & iF-M & 78 & 29 & 9 & 3 & 77 & 29 & 26,723 \\
\hline$y w s n$ & & 3 & $\ldots$ & 0 & $\ldots$ & 2 & $\ldots$ & 80,808 \\
\hline
\end{tabular}

Comparison between iF-M and ( $\mathrm{vF}-\mathrm{M}+\mathrm{M})$

$$
\begin{aligned}
& y w s n \text { series } \\
& y \text { females, } \chi_{\mathrm{c}}^{2}=3.6, \quad \mathrm{P}=0.06 \\
& \text { fractional } y \text { females, } \chi_{\mathrm{c}}^{2}=9.8, \quad P=0.002 \\
& \text { hyperploid males } \quad \chi_{\mathrm{c}}^{\mathrm{g}}=14.9, \quad P=0.0001 \\
& y \text { ac sc pn sn series } \quad y \text { females, } \chi_{\mathrm{c}}^{2}=0.77, \quad \mathrm{P}=0.38 \\
& \text { fractional } y \text { females } \chi_{\mathrm{c}}^{2}=0.006, \mathrm{P}=0.94 \\
& \text { hyperploid males, } \chi_{\mathbf{c}}^{\mathbf{z}}=4.5, \quad \mathrm{P}=0.03
\end{aligned}
$$

Comparison within iF-M, between $y w$ sn and $y$ ac sc pn sn series

$$
\begin{array}{lll}
y \text { females, } & \chi_{\mathrm{c}}^{2}=0 \cdot 06, & \mathrm{P}=0.80 \\
\text { fractional } y \text { females, } & \chi_{\mathrm{c}}^{2}=6 \cdot 7, & \mathrm{P}=0.009 \\
\text { hyperploid males, } & \chi_{\mathrm{c}}^{2}=3.4, & \mathbf{P}=0.06
\end{array}
$$

From this table it is seen that in the offspring of $y w s n$ females the higher rates of both fractionals and hyperploids from impregnated females (iF-M) as compared with the rates from the other two modes of irradiation (excluding series $\mathbf{F}$ ) is clearly significant. In the case of the offspring of $y$ ac sc pn sn females there is no difference in the rates of fractionals in these three modes of irradiation. And, when a comparison is made of the rates of fractionals from impregnated females between the $y w s n$ and the $y$ ac sc pn sn series, this difference is also significant. From this it must be concluded that the "nature" of the strain from which the mothers of the fractionals come is of 
influence upon the rates of these fractionals. From table 4 it is also seen that the rate of hyperploids is higher in the offspring of $y$ ac sc pn sn females than in the offspring of $y w s n$ females. But as this is so regardless the mode of irradiation, this has nothing to do with the questions dealt with in the present article. The causes here at work are discussed by Lüning (1954).

\section{DISCUSSION}

The phenotype of the fractional yellow females is, as pointed out earlier, partly yellow and partly grey. They should, however, be clearly distinguished from variegated yellow of the mottled type. These variegates are of two kinds. The majority have a limited number of yellow hairs intermingled between the grey hairs, their general appearance is grey and they may be found in the progeny of crosses between $y$ females and $M_{5}$ males also without irradiation. These variegates are not separately classified in the tables but included in the totals. The second type of variegates is practically wholly yellow with a few grey hairs. They are in the tables included among the yellow females but their numbers are given in footnotes.

The fractional yellow females are not mottled. There is on them a sharp borderline between yellow and grey. The body surface is usually divided into two parts, one yellow and one grey, but may also be broken up into more parts which are alternatingly yellow and grey. Though the fractionals are wholly female the difference between variegates and fractionals may be compared to the difference between intersexes and gynandromorphs. The mosaicism of a variegated or of an intersex is not due to dissimilarities in the genotypic make-up of their cells. The mosaicism of a fractional or of a gynandromorph is, on the contrary, due to a difference in the chromosomal constitution in the different parts of the body: in gynandromorphs one part of the body is female and one part male; in fractionals one part is heterozygous for yellow and one part homozygous.

The truth of this distinction between fractionals and variegates should be ascertainable by testing from their progeny: The $\mathrm{M}_{5}$ carrying daughters of a variegated should be variegated, whereas such daughters of a fractional should be wholly grey or, sometimes, wholly yellow. Only three of the female aberrations were actually progeny tested by crossing them to brothers. The first of these was a yellow variegated (yellow Bar with a few grey hairs) from series $\mathrm{vF}-\mathrm{M}(9)$, table 2. Here progeny consisted of $\mathrm{I} 7 y B$ and $34 y$ ac sc pn sn daughters, $24 y$ ac sc pn sn and no $B$ sons. The $y B$ daughters were variegated in that they had a few grey hairs. The second was a fractional yellow female from series $\mathrm{M}(2)$, table 2. Of her daughters 40 were $B, 28$ y ac sc pn sn, I $y$ ac $B$; and of her sons $24 M_{5}$ and 23 y ac sc pn sn. The third was a fractional from series iF-M, table 2 : it was only noted that her offspring showed her ovaries to be 
M5 ly ac sc pn sn. So far as these three progeny tests go they conform thus to the distinction made between fractionals and variegates.

For the discussion it is of primary importance to remember that the types of aberrations included in the tables are all due to mutational processes within the paternal X-chromosomes. It follows that if the rates of some or more of these aberrations are influenced by the nature of the strain from which the mothers are taken and/or by differences in treatment of the mothers, such influences must be brought about by secondary pathways. Furthermore, we know that the majority of the yellow daughters from the cross of yellow females to $M_{5}$ males with irradiated spermatozoa is due to breaks in the $y$-region of the $M_{5}$ chromosome (see Lüning, 1952). We must, therefore, conclude that a fractional yellow daughter from the same cross is due to a break in that region, but in only one of the chromosome's two chromatids.

The results of the statistical analyses of the preceding section may be summarised as follows.

I. If among the progeny of $y w s n$ females a comparison is made between the number of aberrations, on the one hand, when irradiation of the spermatozoa is made on impregnated females ( $\mathrm{iF}-\mathrm{M}$ ) and, on the other hand, when the spermatozoa are irradiated in the males ( $\mathrm{vF}-\mathrm{M}$ and $\mathrm{M}$ ), a clearly significant heterogeneity is found. This difference in the rates is very marked for fractionals and hyperploids but it is perhaps questionable whether there is any true difference in the rates of yellow females.

2. In the progeny of yacsc pnsn females the corresponding difference in rates between $\mathrm{iF}-\mathrm{M}$ and ( $\mathrm{VF}-\mathrm{M}$ and $\mathrm{M}$ ) is restricted to the hyperploids.

3. If a comparison is made of the rates of fractionals within the $\mathrm{iF}-\mathrm{M}$ series, between the progenies of $y w s n$ females and of $y$ ac sc pn sn females, the difference is significant.

4. When the rates of fractionals within the series in which the spermatozoa were irradiated in the males are compared, on the one hand when combined with irradiation of the virgin females (vF-M) with, on the other hand when the males only are irradiated (M), a significant difference was, at one occasion, found in the progeny of y $w$ s $n$ females.

5. This difference was not found when a repeat of the experiment was made at a later occasion; and it was not found in the progeny of $y$ ac sc pn sn females.

6. Irradiation of virgin females only does not increase the rates of any of the aberrations above the spontaneous rates.

The statement under point I agrees exactly with our findings concerning the production of sex-linked lethals (Bonnier and Lüning, 1953). We found there that when crossing $y w s n$ females to $M_{5}$ males and irradiating the sperm, a higher rate of sex-linked lethals was produced if the sperm was irradiated in impregnated females 
than if it was irradiated in the males. A small-scale experiment showed that the same result occurred if wild type Canton $S$ males were used instead of $M_{5}$ males. As a possible explanation we suggested that the spermatozoa are in a more sensitive state when stored in the somewhat more movable condition in the females than in the more rigid bundles within the testes. The statement under point 3 shows, however, that the differences cannot be solely due to changes in states of the spermatozoan nuclei. It must be supposed that the "nature" of the females, in the progeny of which the aberrations occur, also exerts an influence.

We will discuss three possible directions in which the explanation may be thought to be sought. In the first place the differences may be due to different oxygen tensions. Several investigators have shown that if X-ray irradiation is made in gas of lower oxygen concentration than in air, the number of chromosome breaks will be reduced (see Hollaender, Baker and Anderson, I95I for review). It seems, however, not to be finally settled if this effect is due to a decrease in the number of primary breaks or to an increase in the number of restitutions of broken ends (Baker and Edington, I952; Baker and von Halle, 1953). If now the differences found in the rates of the present study are due to differences in oxygen tension it would be necessary to suppose that, though all our experiments are made in air, the receptacles of $y w s n$ and of $y$ ac sc pn sn females have different oxygen tensions. It would also be necessary to suppose that these differences act selectively on different types of aberrations.

As a second way of explanation we may think of chemical protection. It is known that a number of chemical compounds protect against irradiation damage (see Hollaender, Baker and Anderson, I95I for review). It would then be thinkable that there are different amounts of protecting stuffs in the walls of the testes and of the receptacles, and that such differences also are to be found between the receptacles of females from different strains. It would, however, still be difficult to explain why irradiation of the spermatozoa within the females increases the rate of fractionals and of hyperploids in the progeny of $y w s n$ females but only of hyperploids in the progeny of $y$ ac sc pn sn females.

The third way of explanation takes differences in energy levels into account. During the last few years different investigators have, especially in connection with studies on the increasing effect on chromosome breaks from infra-red irradiation when combined with X-ray irradiation in Drosophila and Tradescantia, described the phenomenon in terms of such levels and of surmountings of energy barriers (Swanson and Hollaender, 1946 ; Swanson, 1947, 1949; Yost, I95I ; Swanson and Yost, I95I ; McElroy and Swanson, I95 I ; Yost, 1952). The energy coming (indirectly) from an X-ray quantum may, according to this view, sometimes be too weak to produce a break but the chromosome molecule in question may still 
have absorbed an amount of energy not much below what is necessary for surmounting the barrier, i.e. for producing a break. This state of the molecule may be metastable, i.e. the molecule may remain for a considerable time in an energy valley situated at a higher level than the initial state. If this valley is not far below the peak of the energy barrier and if an extra amount of energy, which may be too small to have any effect by itself, is added, for instance by infra-red irradiation, the molecule may jump over the barrier and the break will be fulfilled. Now, applying such considerations to our cases, we should suppose that X-ray irradiation of the fluid in the receptacles (or perhaps of some other female tissue) gives to its molecules a supply of energy which, by secondary paths, may be added to the energy of the irradiated spermatozoan chromosome loci. The X-ray irradiation of the females and, according to this hypothesis, the supposed production thereby of an energy source should thus here correspond to the infra-red irradiation.

One of the results of the present study could perhaps be explained on the assumption of the validity of the energy level hypothesis. In point 4 it was stressed that the rate of fractionals was, in the first set of experiments, enhanced by combining irradiation of the males with irradiation of the virgin females. The fractionals are produced when the paternal X-chromosomes have one chromatid broken and one unbroken. Such a thing may happen in different ways. But for those cases which constitute the surplus when the rate in the $\mathrm{vF}-\mathrm{M}$ series is compared to that in the $\mathrm{M}$ series of table $\mathrm{I}$, we may imagine that, from a primary process, a suitable locus of the chromosome is raised to a metastable state not far below the peak of the energy barrier. If this state could remain to after splitting there would be two homologous loci of which one or both could be excited. Now, it would seem to be much more likely that an extra amount of energy (from a secondary source produced by irradiating the female tissues and enough for the production of a break) would be absorbed in one only than in both of these loci. And this is the same as to say that one is much more likely to find an increase of fractional yellow females than of full yellow females whether both or only one of the chromatid loci remained in the metastable state.

Whichever of the explanations we may choose there will remain several unexplained experimental facts. It seems to me that the energy level assumption gives the best fit to the differences in the rates of fractionals between the $\mathrm{vF}-\mathrm{M}$ and the $\mathrm{M}$ series from table $\mathrm{I}$. But it is very probable that other circumstances are influential in causing the differences found with regard to the other types of aberrations, and that possibly also different forces are at work which interact in the production of the end result. 


\section{SUMMARY}

I. In a preceding article it was shown that the rate of $\mathrm{X}$-ray induced sex-linked lethals in sperm of Drosophila melanogaster is increased if the sperm are irradiated in impregnated females when a comparison is made with the result of irradiation of the males. The present study shows that the same is true with regard to other kinds of X-ray induced aberrations in the male gametes containing the $M_{5} \mathrm{X}$-chromosome, viz. aberrations which after crossing to yellow females produce hyperploid sons, fractional yellow daughters and possibly also full yellow daughters.

2. It is shown that this effect is influenced by the nature of the strain of yellow females to which the $M_{5}$ males are crossed, insofar as the frequencies of the fractional yellow daughters are significantly different when comparison is made between two such strains.

3. In one series of experiments it was found that the rate of fractional yellow daughters produced by irradiation of males was significantly increased if the females were irradiated prior to mating. In a repeat of the same type of experiment, performed at a later occasion, no such increase was found; but comparing the rates of fractional yellow daughters which were found on the two occasions, the difference was found to be statistically significant. Any influence of irradiating the females only was not found.

4. Three possible ways of causing these results are discussed, viz. differences in oxygen concentration, differences in chemical protection, and a system of metastable energy levels.

\section{REFERENCES}

BAKER, W. K., AND EDINGTON, c. W. I952. The induction of translocations and recessive lethals in Drosophila under various oxygen concentrations. Genetics, $37,665-677$.

BAKER, W. K., AND VON HALle, ELIzABETH s. 1953. The basis of the oxygen effect on X-irradiated Drosophila sperm. P.N.A.S., 39, 1 52-16r.

BELGOVSKI, M. L. I938. Influence of inert regions of chromosomes on the frequency of occurrence and type of changes in the adjacent active sections. Bull. Acad. Sci. USSR, Series Biol., 5-6, 1 о 7 -1 $03^{6} 6$.

Belgovski, M. L. I939. Dependence of the frequency of minute chromosome rearrangements in Drosophila melanogaster upon X-ray dosage. Bull. Acad. Sci. USSR, Series Biol., 2, I59-I 70.

BONNIER, G., AND lüNING, K. G. 1953. Sex-linked lethals in Drosophila melanogaster from different modes of X-ray irradiation. Hereditas, 39, 193-200.

BONNIER, G., LÜNING, K. G., AND BARBRO ARNBERG. I $95^{2}$. On a possible mutagenic effect of X-rayed egg cytoplasm. Hereditas, 38, 1 09-I 12.

HOLLAENDER, A., BAKER, W. K., AND ANDERSON, E. H. I95I. Effect of oxygen tension and certain chemicals on the $\mathrm{X}$-ray sensitivity of mutation production and survival. Cold Spring Harbor Symposia on Quantitative Biology, 16, 3 I 5-326.

LÜNING, K. G. I952. Studies on the origin of apparent gene mutations in Drosophila melanogaster. Acta Zool., 33, 193-207.

LÜNING, K. G. I 954. Variations in the breakability of chromosomes in mature spermatozoa of Drosophila melanogaster from different modes of irradiation. Heredity, 8, 2 I I-223. 
MCELroy, W. D., AND SWANSON, C. P. 195I. The theory of rate processes and gene mutation. Quart. Rev. Biol., 26, 348-363.

SWANSON, C. P. I947. The effect of infra-red treatment on the production of X-rayinduced changes in the chromosomes of Tradescantia. Amer. F. Bot., 34, I 2 a.

sWANson, C. P. 1949. Further studies on the effect of infra-red radiations on $\mathrm{X}$-ray-induced chromatid aberrations in Tradescantia. P.N.A.S., 35, 237-244. SWANSON, c. P., AND HOLLAENDER, A. 1946. The frequency of chromatid breaks in Tradescantia as modified by near infra-red radiation. P.N.A.S., 32, 295-302. SWANSON, C. P., AND YOST, H. T. I95I. The induction of activated, stable states in the chromosomes of Tradescantia by infra-red and X-rays. P.N.A.S., 37, 796-802.

Yost, H. T. 1951. The frequency of X-ray induced chromosome aberrations in Tradescantia as modified by near infra-red radiation. Genetics, 36, I 76-184.

yosт, н. т. 1952. The effect of intensity of infra-red on X-ray induced chromosome aberrations in Tradescantia. Genetics, 37, 457-468. 